DOI: 10.12957/demetra.2015.15490

\title{
O segredo de um cuscuz: alimentação e identidade
}

\section{Theseret of acascas food and identity}

Guida da Silva Cândidoº

1 Universidade de Coimbra, Centro de Estudos Clássicos e Humanísticos da Faculdade de Letras. Coimbra, Portugal

Correspondência / Correspondence Guida da Silva Cândido

Museu Municipal Santos Rocha - Rua Calouste Gulbenkian 3080-084, Figueira da Foz, Portugal

E-mail: guida.silva.candido@gmail.com

\section{Resumo}

A natureza humana conduz o homem na busca permanente de experiências sensoriais. Nada une o homem de forma tão evidente como esse propósito do prazer sensorial. A alimentação, o ato de comer, representa mais do que a necessidade física, biológica e primária de sobrevivência. É também uma ação que envolve, ou pode envolver, cada um dos sentidos, de forma a experienciar uma sensação nova, diferente e aprazível. O cinema encontra-se nas mesmas circunstâncias: pressupõe a busca de sensações. Em ambos os campos, cinematográfico e gastronômico, ocorrem perceções de natureza sensorial distintas, mas que desembocam ambas na possibilidade de relacionar os diferentes sentidos e as sensações que daí resultam. Aqui, pretende-se demonstrar como o cinema constitui uma representação da identidade cultural e social. Analisa-se $O$ segredo de um cuscuz sob o ponto de vista da alimentação e das relações que se estabelecem entre as personagens à volta de um alimento.

Palavras-chave: Ciências Sociais. Antropologia. Sociologia. Alimentação. Cinema.

\section{Abstract}

Human nature leads man in constant search of sensory experiences. Nothing unites manking as that way of sensual pleasure. Food, the act of eating, is more than a physical, biological need and primary survival. It is also an action that involves or may 
involve, in each direction, so as to experience a new, different and pleasant feel. The cinema is located in the same circumstances: presupposes the search of sensations. In both fields, cinematic and gastronomic occur perceptions of different sensory nature, but that flow both in the possibility of linking the different senses and feelings that arise from it. Here, we intend to demonstrate how cinema constitutes a representation of cultural and social identity. We analyzes The secret of a couscous in the perspective of feeding and the relationships established between the characters around food.

Key words: Social Sciences. Anthropology. Sociology. Food. Movies.

Podemos viver sem amigos; podemos viver sem livros; mas nenhum homem civilizado consegue viver sem cozinheiros.

Owen Meredith

\section{Introdução}

Nas palavras do Historiador Kenneth Kiple, na sua obra Uma história saborosa do mundo, ${ }^{1}$ enquanto explica a história dos condutos no Norte de África, ele afirma, em relação ao cuscuz que:

inicialmente, este consistia num farelo de grão grosseiramente moído que era transformado numa espécie de pasta de cereal chamada kuscussù. Todavia, à medida que a confeção foi evoluindo, começou a fazer-se uma massa moldada em formas que iam desde grãos de bolinhas, posteriormente preparados em recipientes de cerâmica de vários andares, onde se cozinhavam vegetais em lume brando e talvez cordeiro, sendo que o cuscuz era cozido na parte de cima, ao vapor. Do Norte de África, o cuscuz espalhou-se para o Mediterrâneo.

Partindo deste alimento identitário de um povo e de uma cultura, Abdellatif Kechiche, com o filme $O$ segredo de um cuscuz, ${ }^{2}$ constrói uma narrativa que traduz as relações familiares e comunitárias dos emigrantes magrebinos no país de acolhimento, França, no atual século XXI.

Slimane vive e trabalha na cidade costeira de Sète, França. Após mais de três décadas de trabalho, é dispensado e depara-se com o sentimento de inutilidade. Com o apoio da família e da comunidade imigrante árabe, procura realizar o sonho de abrir um restaurante num barco, dando sentido à sua vida e ao seu papel de patriarca. 
Pretende-se, nesta análise, estabelecer a relação entre o cinema e alimentação enquanto fonte histórica e de análise social. No caso concreto, parte-se do alimento em destaque, o cuscuz, numa tentativa de compreender o contexto particular de conflito vivido pela população magrebina em França no início deste século.

O segredo de um cuscuz dá a conhecer o contexto da comunidade árabe no país de acolhimento, relacionando aspectos distintos da integração, da precariedade laboral, da interação com outras comunidades imigrantes e das relações familiares assentes em valores de solidariedade e identidade comum. Reflete sobre questões importantes da atualidade, presentes na cultura ocidental, nomeadamente a instituição família, o fenômeno da emigração, a xenofobia, o mundo do trabalho, em particular a dificuldade crescente de assegurar o sustento regular para o agregado familiar, a realização pessoal/profissional enquadrada num contexto de validade social e, finalmente, a política.

\section{0 cuscuz enquanto alimento integrador}

Slimane tem um sonho: abrir um restaurante num barco. Esse projeto nasce quando se depara com o cenário de desemprego. O restaurante materializa a sua possibilidade de sobrevivência.

O cuscuz de peixe que a ex-mulher cozinha é o elo de união entre todos. De certa forma, é a revelação de um ato de amor. Um amor generoso e desprendido. Souda não quer recuperar o casamento com Slimane, contudo, ele é família, é um dos seus e é importante que ele tenha uma segunda oportunidade. O cuscuz, tanto no almoço de família, como no jantar inaugural, ou a oferta à vizinha e ao mendigo (que, talvez metaforicamente, é o único - ou o primeiro - a comer cuscuz na noite de inauguração do restaurante), é o elemento integrador e agregador.

Na incontornável obra de Brillat-Savarin, A fisiologia do gosto, ${ }^{3}$ o autor estabelece a relação entre alimentação e felicidade, distinguindo o ato de comer primário e o alimentar humano. Para BrillatSavarin, o prazer da mesa reside essencialmente na amizade e na convivência que esta permite. ${ }^{3,4}$

Também na obra de Kechiche ${ }^{2}$ se estabelece a indissociabilidade da mesa enquanto elemento de convivialidade e felicidade.

\section{0 almoço em família}

O estudo da sociabilidade e da gastronomia ao longo da História vem demonstrando a importância da comensalidade. O ser humano retira prazer e alegria do ato de comer. A mesa, que serve de plataforma ao ato de comer, mas também à sociabilidade, é o local onde se reforçam os «laços entre as pessoas no interior da célula familiar e também para afirmar a identidade dos diversos grupos sociais.» ${ }^{5}$ 
Parece oportuno fazer aqui a distinção entre o ato de alimentar-se e o ato de comer. Como já vem sendo hábito por parte de diversos autores, apresenta-se a diferença que estabelece uma fronteira clara entre a ação apenas nutricional e de sobrevivência, e o ato social relacionado com «usos, costumes, protocolos, condutas e situações [...] o que se come é tão importante quanto quando se come, onde se come, como se come e com quem se come». ${ }^{6}$

$\mathrm{O}$ ato de comer com os outros acontece com mais regularidade em família. No contexto familiar, as situações de permanência à mesa e de convívio são - ou foram - mais regulares e comuns. Apesar de cada vez com mais intensidade a alimentação se identificar de forma mais afastada no universo doméstico, tem se afirmado como um mercado de consumo de massas, registrando a restauração, evolução e crescimento consideráveis, diminuindo o protagonismo da cozinha doméstica, que inicialmente funcionava ao redor da lareira. A cozinha era o coração da casa, o local onde as relações familiares se cimentavam e consolidavam.

O quotidiano familiar vem sofrendo alterações profundas devido aos fenômenos de urbanização e industrialização, sobretudo a partir da segunda metade do século XX. Fenômenos como a entrada das mulheres no mundo do trabalho profissional, as melhorias significativas nas condições de vida e acesso à educação, a generalização do automóvel e ainda a progressiva capacidade de aceder ao lazer, férias e viagens, constituem fatores relevantes nessas alterações e na relação que desde então se verifica com a permanência no lar das famílias, em particular das mulheres, e as consequentes alterações de hábitos no que concerne à dinâmica de sociabilidade e o conjunto de relações à mesa.

Naturalmente, com este conjunto de circunstâncias, as refeições fora do lar sofrem um aumento significativo, provocando o desenvolvimento e crescimento da restauração, tanto nas empresas, como nas escolas e coletividades, com a implementação de serviços diferenciados como é o caso distinto do self-service. ${ }^{1}$

Apesar do fenômeno do aumento das refeições fora do lar, a tradição do almoço em família - sobretudo ao domingo - é um aspecto social enraizado e sujeito a alterações menos profundas e de implementação mais demorada ao longo das últimas décadas. Embora o avanço do espaço público constitua um fenômeno que invadiu o espaço doméstico e alterou algumas expressões das relações familiares, a casa permaneceu como o domínio do privado, estabelecendo a fronteira entre a vida pública e privada, embora alguns aspectos desta última também ocorram em espaço público. Acontece igualmente uma permeabilidade da casa ao espaço exterior: a inclusão, no lar, de parentes, amigos e vizinhos. A atualidade das palavras de Pereira Brandão, no final do século XIX, quando define o lar como «um assunto inesgotável de estudo, porque além de conterem os destinos da família, são também o foco onde os estranhos se vêm reunir, atraídos pelo estrondo das festas, pela liberdade do amor e pelas relações mútuas de mil interesses ${ }^{7}$ serve de forma clara para ilustrar o almoço de família que acompanhamos nesta história do século XXI. 
A teia de afetos que une todos à mesa, no almoço de cuscuz, é reveladora da cumplicidade entre os intervenientes. A espontaneidade da conversa que se desenrola durante a refeição permite construir as relações afetivas que os unem. A conversação resulta como uma prática de convivialidade, herança de tempos passados e também fenômeno quotidiano, transversal aos diferentes grupos sociais, com graus diferentes de relevância e permanência. Os divertimentos e meios de comunicação que a Revolução Industrial conquistou alteraram o peso que a conversação alcançou nas sociedades tradicionais. A prática da conversação surgia de forma particular nos manuais de civilidade, onde se defendiam a elegância e o polimento nessa prática. Em Portugal, teve defensores acérrimos, como Antônio Feliciano de Castilho, que via na conversação «a convivência de famílias entre si e da família com outras famílias; a conversação, que é para tantos o seu único teatro, a sua única filarmónica, a sua única literatura; que é ela, esta maravilhosa e boníssima coisa [...], senão a mais natural, a mais antiga, a mais incondicionada, a mais absoluta e a mais universal de quantas festas se endereçam ao prazer?! [...] para o banquete da conversação contribuem o entendimento, a memória, a fantasia, os gostos, os interesses, os afetos de cada um. Ativos e passivos ao mesmo tempo, todos dão e todos recebem; dão alguma coisa; recebem muito mais. Aprendem-se os homens, aprende-se a vida, aprende-se o trato, aprende-se a benevolência, dilata-se o coração, fogem as horas não contadas, nascem ou melhoram-se as amizades, semeiamse ou reverdecem, ou robustecem-se os amores». ${ }^{8}$

Também no filme $O$ segredo de um cuscuz, o lar de Souda, a ex-mulher de Slimane, é o ponto de convergência da família e amigos. É à mesa, durante o almoço domingueiro de família, que as conversas em torno da comida, do amor, das diferenças culturais se desenrolam. Os interesses e os afetos manifestam-se de forma natural e espontânea. A capacidade de Souda de reunir todos, sob o pretexto de um prato de cuscuz, é reveladora do papel que a comida representa nas sociedades atuais, em que as diferenças culturais e os distintos contextos em que os indivíduos gravitam são atenuados. A comida tem o duplo papel de distinguir como de aproximar, uniformizar. Se por um lado existe a questão identitária, definidora do indivíduo enquanto pertença a um grupo, há também o papel de aproximação de culturas, de universos distintos. As barreiras que existem nas duas culturas que se cruzam na narrativa não são geradoras de distância e afastamento, antes permitem a descoberta de mundos diferentes. Mais uma vez, a culinária une pessoas de origens distintas, mas que na mesa acabam por buscar o mesmo, o prazer sensorial que a comida permite.

A identidade reforça-se pelo sentimento de pertença. O cuscuz, no seio da família, tem uma função sociabilitária. Os temas de conversação são os mesmos: o amor e a língua árabe. Ambos aproximam e afastam. Contudo, o prazer associado àquela refeição é o mesmo para todos. $\mathrm{O}$ deleite com que a refeição se prolonga é manifestado por todos quanto partilham o cuscuz. Souda é elogiada pelo seu cozinhado. Ela tem noção do seu papel enquanto mulher que alimenta a família e estende essa dádiva aos de fora do contexto familiar. Embora seu casamento com Slimane tenha chegado ao fim e não haja, por parte dela, o desejo de o retomar, os laços de amor e solidariedade 
mantém-se. Souda partilha à mesa o seu cuscuz, no seu lar, mas reserva para Slimane e para a vizinha dois pratos desse alimento, para esse exercício de partilha, que se traduz também em solidariedade. É esse um dos segredos do cuscuz, o reforço dos laços de solidariedade.

Slimane recebe a visita dos filhos Majid e Riadh, que lhe levam o cuscuz. E o ciclo de partilha verifica-se também aqui, quando Slimane o partilha com Rym, sua enteada. Enquanto dura a refeição, Slimane fica sujeito às diferentes opiniões sobre seu futuro, ainda que seu desejo seja abrir um restaurante.

\section{0 restaurante}

Não cabe aqui fazer a história dos restaurantes desde seu surgimento até à atualidade, mas pode-se apontar a gênese do termo para que se entenda o princípio do que é o restaurante, um dos aspectos também realçados no filme em análise.

Quando, cerca de 1765, Boulanger abriu seu estabelecimento em Paris, próximo do Louvre e nele iniciou a venda de restaurats ou «caldos restaurantes», isto é, suculentos caldos à base de carnes para restaurar as forças enfraquecidas, não tinha certamente noção do fenômeno que tinha iniciado e da disseminação do termo "restaurante". Desde o fim da Idade Média que a palavra «restaurante» designa estes caldos suculentos feitos à base de aves de capoeira, carne de vaca, várias raízes, cebolas, ervas de tempero e, consoante as receitas, especiarias, açúcar cândi, pão torrado ou cevada, manteiga, bem como produtos aparentemente tão insólitos como pétalas de rosa secas, passas de uvas de Damasco, âmbar, etc. Para atrair os fregueses, Boulanger escreveu na fachada do seu estabelecimento esta frase evangélica: «Venite ad me omnes qui stomacho laboratis et ego vos restaurabo.» ${ }^{9}$

O termo impôs-se e, na atualidade, temos em França e em Inglaterra o restaurant, em Itália o ristorante e em Espanha e Portugal o restaurante. Já extrapolou as fronteiras da Europa alcançando locais tão distantes como Tóquio, Hong Kong, Banguecoque, Rio de Janeiro ou Cairo. Também os cozinheiros franceses continuam a sair de portas com requisições por todo o mundo. Embora a cozinha francesa mantenha uma linha, ainda que em constante renovação, a tendência atual é a de sua permeabilidade à influência estrangeira, nomeadamente de suas comunidades imigrantes. ${ }^{9}$

O restaurante de Slimane, especificamente o barco-restaurante, materializa sua possibilidade de sobrevivência. Uma sobrevivência que acontece não ao nível físico, mas antes no nível mental. Representa, no filme, dois aspetos distintos e interligados na progressão da narrativa. Por um lado, é o mote para sua afirmação e recuperação enquanto indivíduo, enquanto homem válido para sua família, sua comunidade e a sociedade de uma forma geral. Com um sentimento de inutilidade que dele se apodera, sua alternativa é construir um projeto que de novo lhe permita obter o respeito da família e por si próprio. 
Por outro, constitui uma forma de distinção cultural e identitária, mas igualmente integradora. Slimane é de origem magrebina, culturalmente formado sob os preceitos árabes, tem orgulho na sua identidade, na sua comunidade, mas é um homem a viver em território francês, e é como tal que quer ser reconhecido, um homem empreendedor que responde aos desejos dos seus pares, mas também ao gosto de experienciar algum exotismo na relação com a comida, por parte dos franceses.

Este constitui o segundo segredo do cuscuz. O cuscuz para Slimane. O papel na sua relação enquanto indivíduo e enquanto membro de duas comunidades: a de origem e a de acolhimento.

O cuscuz é analisado aqui como um alimento âncora e revelador da miscigenação cultural. De acordo com os estudos de Santos, «a formação do gosto alimentar não se dá, exclusivamente, pelo seu aspecto nutricional, biológico. $\mathrm{O}$ alimento constitui uma categoria histórica, pois os padrões de permanência e mudanças dos hábitos e práticas alimentares têm referências na própria dinâmica social. Os alimentos não são somente alimentos. Nenhum alimento que entra em nossas bocas é neutro. A historicidade da sensibilidade gastronômica explica e é explicada pelas manifestações culturais e sociais como espelho de uma época e que marcaram uma época.» ${ }^{10}$

Visto assim, o cuscuz, alimento identitário da comunidade árabe em Sète, é de facto o alimento que poderá unir as duas comunidades, que serve de elo comunicante entre culturas e comportamentos sociais distintos e distantes.

\section{A instituição "família"}

A família é um dos recursos marcantes na narrativa de $O$ segredo de um cuscuz. É a matériaprima das dinâmicas relacionais. Fundamentalmente com o papel de congregar e unir os diferentes elementos, a família de sangue e a família resultante de afinidades reforçam os laços de solidariedade e entreajuda. Concorrem para a construção do protagonista e são, simultaneamente, responsáveis pelo desfecho inglório e o desmoronamento do projeto de Slimane.

Souda representa a matriarca, a líder do clã, a mulher abnegada e catalisadora do bem-estar geral. Não apenas da família, mas igualmente dos que lhe são próximos ou dos carenciados e negligenciados pelas estruturas sociais responsáveis. Sua conduta nem sempre concorre para a felicidade dos diferentes elementos da família, em que os laços de sangue determinam comportamentos pouco consensuais.

Ao longo da narrativa do filme, observam-se os diferentes papéis exercidos pela família, as mais das vezes congregadora, mas também separadora. 


\section{Congregadora}

Impulsionado inicialmente por Rym, sua enteada, e posteriormente por toda a família e a comunidade árabe onde está integrado, Slimane adquire e recupera um barco devoluto e constrói o restaurante. Essa recuperação poderá ser uma metáfora: sua recuperação. O renascer da esperança, de uma nova vida, da sua dignidade.

A determinação de Slimane é alimentada sobretudo por Rym. Mais do que qualquer outra personagem, a enteada procura, desde o momento da gênese do projeto, contribuir para o sucesso da empreitada.

A relação de Slimane com Rym será, eventualmente, a que melhor define uma ligação familiar de amor e dedicação. Desde o início da narrativa, a personalidade de Rym e sua afetividade por Slimane surgem de forma transparente e constante. Na primeira sequência, ninguém recebe o peixe oferecido por Slimane como a sua enteada. Souda recusa-o, Karima desvaloriza-o, Rym fica radiante e agradece ostensivamente a Slimane. Mais do que o valor atribuído à dádiva do peixe, revela neste ato um profundo sentimento de amor e de comunhão com aquele que representa para ela a figura paterna. Por isso, seu empenho na concretização do sonho/projeto de Slimane é constante. É incansável nas diligências burocráticas; na congregação de esforços e envolvência da mãe, Latifa, e da comunidade árabe com quem partilham o espaço comunitário habitacional; na desvalorização das sugestões dos filhos de Slimane de regressar à sua terra; e, finalmente, no plano final de entreter os convidados com sua dança sensual, enquanto se tenta resolver o drama da falta do cuscuz.

Com o desenvolvimento da narrativa, o espectador tem acesso a outras personagens também elas com um papel agregador relevante. Os filhos de Slimane, ainda que com algumas hesitações iniciais, acabam por funcionar como elementos determinantes na construção do projeto do pai. Em termos concretos, destaca-se Riadh, que ajuda o pai na recuperação do barco. Sua ajuda é preciosa nesse contexto de trabalho braçal e de envolvimento no projeto. Com uma personalidade mais branda que os outros irmãos, é colaborador e pacificador e o único que nutre afeição por Rym. Um sentimento que nada tem de fraterno. Rym personifica para ele a mulher-desejo.

Olfa comporta-se de forma idêntica a Riadh. De forma mais discreta, seu papel é igualmente de apoio ao sonho do pai. Acredita no amor de Souda por Slimane e parece ser a única a ter esperança no poder desse amor e na possibilidade de um reatamento da relação dos progenitores. Durante a festa, exerce papel determinante na concretização de diversas tarefas, nomeadamente a responsabilidade de transportar o cuscuz de casa para o barco. Confiante na distribuição de tarefas, julga que Majid, com quem realizou a viagem e o transporte do cuscuz, transpôs para o barco todas as panelas com os alimentos. $\mathrm{O}$ choque perante a descoberta da falta da refeição reflete-se numa angústia desesperada em contactar por telefone o irmão que se ausentou da festa, transportando no carro a panela com o ingrediente principal, o cuscuz! 
Karima, a filha mais velha de Slimane e Souda, exerce algum domínio nas relações familiares - aliás, seguindo a matriz da progenitora. De alguma forma, as mulheres dessa narrativa são, todas elas, mulheres com personalidades fortes, determinadas, habituadas a ultrapassar as mais diversas adversidades. Contudo, a sua força intrínseca encaminha-as para seus objetivos com uma obstinação tal que a fronteira entre a agressividade e a determinação é tênue.

Nos conflitos familiares, nomeadamente na relação tempestuosa entre Majid e Julia, Karima é o elemento que exerce atitude mais assertiva e coerente. Não pactua com o comportamento adúltero do irmão, censurando-o e procurando que ele reflita sobre sua conduta. Simultaneamente, alerta Julia para suas manifestações públicas de revolta e tristeza, mostrando que os conflitos familiares devem ser resolvidos no espaço privado, de forma adulta e de forma a não afetar as relações familiares mais alargadas.

Apesar da pouca simpatia que nutre pela segunda família do pai, Rym e Latifa, consegue, com esforço, demonstrar um comportamento amistoso e pacífico para com ambas. Os sentimentos manifestados na festa de inauguração do barco-restaurante conduzem invariavelmente a uma busca de concretização e resolução de todos os problemas e conflitos, como garantia do sucesso do projeto do seu progenitor. Slimane é o elemento agregador de todas estas personagens. Todos convergem para a derradeira recuperação do homem, seja ele familiar ou amigo.

Se antes de Slimane adquirir o barco, Majid o incentiva a voltar à terra, acaba por se envolver, como todos os restantes, no objetivo de concretizarem o projeto do pai. Contudo, seu caráter pouco recomendável e o individualismo e egoísmo revelados na sua permanente conduta determinam o insucesso da aventura desta família.

A personagem Latifa não tem um comportamento homogêneo ao longo da narrativa; sua relação com Slimane oscila entre a entrega e afeto e a decepção e demissão. Embora o companheiro encare com desolação sua incapacidade de lhe oferecer estabilidade, Latifa não encara o relacionamento de ambos como um exercício de poder. Contudo, verificam-se momentos em que se sente defraudada e abandona o sonho de Slimane. Num último instante, deixa-se convencer pela filha e abraça a causa que move todos. Apesar de não ser uma cozinheira de excelência, como Souda, tenta, no epílogo, salvar a festa e prepara o cuscuz.

Como se refere anteriormente, cabe a Souda o papel de unir, de congregar através da comida. Transforma esse alimento no ponto fulcral da narrativa: o cuscuz no seio familiar; o cuscuz como dádiva; o cuscuz enquanto possibilidade de salvação física e psicológica de Slimane; o cuscuz como reforço do sentimento de pertença e identitário; o cuscuz como mecanismo diferenciador e o cuscuz gerador da catástrofe, do desmoronamento dum sonho, que conduz a um desfecho que se adivinha fatal para Slimane. 


\section{Separadora}

A família, como já se referiu anteriormente, tem nessa narrativa o papel crucial no desfecho da intriga. Prevalece seu desempenho como sistema agregador, mas não é de negligenciar seu poder enquanto mecanismo separador.

Majid será a personagem cujo caráter contribui de forma mais determinante para o desfecho trágico do sonho de Slimane. Ao longo da narrativa, suas ações são motivadas por objetivos pessoais que não se compadecem com os que o rodeiam, particularmente em relação a Julia, sua mulher. Originária da Europa do Leste, a mulher de Majid sabe-se vítima de traição, tanto do marido, como de Souda, a sogra, que é conivente com o comportamento adúltero do filho, facilitando inclusive suas relações extramatrimoniais.

Julia sente-se abandonada e traída por todos, não só pelo marido, mas também por sua família. Ainda que Karima censure o irmão, procura que Julia lide com seu casamento de forma menos dramática. Slimane, no seu doloroso silêncio, quando é confrontado por Julia com o sentimento de revolta, angústia e desespero, não consegue oferecer nenhuma resposta ou consolo à nora. É apenas mais um dos dramas e contrariedades que se apresentam na sua vida.

Souda representa a matriarca agregadora. É ela que une a família. É seu cuscuz que congrega todos na demanda de concretizar o sonho de Slimane. Apesar desse amor agregador, Souda não acolhe de forma efetiva a nora. Ainda que de forma indireta, contribui para a relação dramática e conflituosa que Julia vive com Majid. A ajuda que a mãe presta a Majid nos seus relacionamentos adúlteros motiva o desapontamento e a ira de Julia. Seus gritos assemelham-se ao de um animal atacado, um ser dilacerado pela dor. A indiferença a esse sofrimento retira a Souda a plenitude enquanto elemento apaziguador.

Os sentimentos e comportamentos sórdidos e infames contribuem para conferir humanidade às personagens, da mesma forma que são importantes os que revelam coragem, ousadia e determinação.

\section{A comunidade}

Partindo das palavras de Carlos Silva a propósito do Cinema enquanto mecanismo de «representação cultural de um determinado grupo, expressando assim também o modo como esse grupo se vê, fica impossível não incluir o cinema no rol dos meios de comunicação que influenciam nessa construção de identidade». ${ }^{11}$ Fica também difícil não estabelecer a ligação da origem cultural do autor do filme com o tema e a comunidade em causa. 
De origem Tunisina, Kechiche emigrou, durante a infância, com os pais, para a França. Com dupla nacionalidade, e bem integrado na realidade francesa, a sua sensibilidade para com as causas dos imigrantes refletem-se na sua obra, em particular neste filme. O seu olhar será certamente diferente e condicionado por seu envolvimento cultural com esta comunidade. A diferença social e as desigualdades são analisadas, bem como as marcas identitárias árabes.

O cinema tem aqui o papel de entretenimento, mas funciona essencialmente como objeto de reflexão. A «relação entre cinema e identidade cultural parte do pressuposto de que o cinema é inegavelmente uma atividade cultural importante no sentido de reflexão de determinado segmento social que veem na tela não só o entretenimento, mas também um espelho ficcional do seu quotidiano, dos seus anseios, dos seus problemas, das suas emoções e até mesmo dos seus sonhos. ${ }^{11}$

Ainda que o enfoque se concentre na comunidade imigrante, será eventualmente mais correto designar as comunidades, pois o filme vive da relação da comunidade árabe com a comunidade local - os franceses.

\section{0 fenômeno da imigração}

Abdel Kechiche integra-se no movimento cinematográfico da diáspora. Este "cinema de imigração" dá enfoque à questão da identidade, simultaneamente individual, comunitária e nacional.

Apesar de muitos autores defenderem que não existe uma comunidade magrebina em França, na verdade existem seis milhões de habitantes de origem norte-africana. Uma comunidade que se distingue por sua cultura cinematográfica, com jovens cineastas pertencentes à terceira geração de imigrantes provenientes de Marrocos, Argélia e Tunísia, como é o caso de Kechiche.

Designados pelos franceses de "beurs", têm em comum o fato de pertencerem a uma geração marcada por preconceitos religiosos e sociais, vivendo entre duas culturas. Oscilam entre a tradição islâmica e a modernidade ocidental. O desafio maior consiste na sua integração na sociedade francesa. Esta realidade é, muitas vezes, o tema deste cinema que não é nem magrebino nem francês, mas que tem como denominador comum a "tematização da busca por uma identidade". ${ }^{2}$

De acordo com um estudo realizado em 2011 pelo Instituto Francês de Estudos Demográficos (INED), ${ }^{13}$ «os imigrantes em França vivem menos segregados do que há 50 anos e os seus filhos residem cada vez menos em bairros pobres», sendo que os níveis de segregação em relação aos imigrantes magrebinos baixaram cinco pontos percentuais. Refere ainda este documento que $72 \%$ dos imigrantes de segunda e terceira gerações vivem fora dos bairros mais pobres, sublinhando a "dinâmica de integração residencial" francesa. 
Em O segredo de um cuscuz, essas relações de integração encontram-se bem exploradas. Da mesma forma o são a busca ou afirmação de uma identidade. Slimane trabalhou uma vida no estaleiro. É dispensado mas sua vontade é permanecer no país que o acolheu. Sente-se incluído nesse espaço. A sugestão dos filhos em regressar à terra não é bem recebida. Seus planos passam por se manter naquele território e construir algo que o mantenha integrado na comunidade local. Oferecer o cuscuz, a marca que o distingue dos franceses, é revelador da necessidade de manter a ligação marcando, no entanto, a sua identidade cultural.

A recorrente questão "somos o que comemos, ou comemos o que somos?"14 surge neste contexto de lembrança gastronômica ou de memória gustativa. O cuscuz traz à comunidade árabe seu sentido de pertença, que não se prende com um território físico, mas com uma herança cultural.

\section{A precariedade no trabalho}

É comum associar o trabalho imigrante ao trabalho precário, embora este não seja um atributo exclusivo do trabalho imigrante. Atualmente, as relações laborais obedecem num crescendo a este paradigma, ramificando-se para todas as categorias de trabalhadores, inclusive os altamente qualificados.

O fenômeno da imigração não é uma questão pontual, mas possui antes contornos de perenidade nas sociedades modernas. Não nos referimos apenas à imigração não qualificada, mas cada vez com maior relevância, também a setores altamente especializados e que exigem elevadas competências e valências.

Pesa sobretudo na imigração menos qualificado o fator "idade". A mancha de população envelhecida alcançou um espetro inimaginável, condicionando de forma marcante o mundo do trabalho e as oportunidades de emprego, alterando de forma inequívoca a própria constituição dos imigrantes.

Kechiche alerta para essas questões sociais na sua narrativa fílmica. O modus operandi do empregador está sujeito às novas realidades socioeconômicas. Slimane não é velho para se reformar, nem é suficientemente novo e útil para desempenhar um trabalho em que se verifica um excesso de oferta laboral. A lealdade de que se acha devedor não entra nos parâmetros do sistema empregador. A economia grita em uníssono a sua dispensabilidade.

Ao longo do filme, outros personagens vão manifestando essa insegurança da precariedade laboral. Este quadro comum na comunidade imigrante será extensível à restante população? 


\section{Xenofobia e políticas de integração cultural}

Os modelos de integração dos imigrantes nos países europeus têm sofrido poucas alterações. Vagas sucessivas de imigração, sobretudo a partir das suas antigas colônias africanas, refletem uma lenta islamização do país. Verifica-se o aumento do número de muçulmanos levando o Estado a uma tentativa de se ajustar a essa realidade, depurando suas referências culturais. O mesmo Estado que foi «introduzindo medidas para conter a exteriorização das expressões culturais e religiosas dos novos imigrantes. A verdade é que uma larga franja da população muçulmana não só se manifesta avessa à sua completa integração social, como afirma que não se identifica com os valores republicanos e a cultura francesa». ${ }^{15}$

Kechiche obriga a esta reflexão com O segredo de um cuscuz. Verificam-se comportamentos xenófobos por parte da comunidade francesa em relação à comunidade árabe? Aceitar o convite para o jantar de Slimane não se pode traduzir por uma atitude paternalista?

A reação à proposta do projeto do barco-restaurante refletiu desde o início a resistência da comunidade local e das entidades responsáveis. Burocraticamente, as dificuldades apresentadas a Slimane adivinhavam a condenação desse sonho. As licenças e empréstimos foram sendo dificultadas, ou mesmo negadas, não obstante a determinação que Rym - mais do que Slimane - emprestou a essa demanda. Não obstante, Slimane, numa derradeira tentativa, pretende mostrar, às autoridades e às forças locais, a validade do seu projeto. Parte do pressuposto de que o arrebatador cuscuz de Souda conquistará o palato de seus convidados, de forma que a aprovação do projeto prevaleça.

Perante a espera do prato principal, os ânimos vão enfraquecendo, e ainda que Slimane, sua família e amigos julguem bem encaminhado o jantar, desde o início que os convidados têm bem definida sua objeção ao projeto. As conversas em torno da proposta vinda de um imigrante suscitam todas as dúvidas e reservas. Não há vontade de integrar este homem e seu sonho no que eles pressupõem ser o seu domínio. Aquele homem e a sua comunidade serão sempre estrangeiros.

\section{Happy end? Não, obrigada!}

"O final feliz, ou happy end, é por vezes imposto pelos produtores aos realizadores. Era o caso do cinema clássico de Hollywood: nas comédias românticas, os heróis de amores não correspondidos deviam encontrar-se no fim para trocar um beijo casto". ${ }^{16}$

Assim é definido o típico final feliz em linguagem cinematográfica. Não encontramos neste filme um final com estas características. Para esse fato concorrem vários fenômenos: as relações tumultuosas entre os diferentes membros da família, essencialmente Majid e Julia, e esta com a 
restante família; o desaparecimento de Majid com a panela de cuscuz; a fraca receptividade da comunidade francesa ao projeto de Slimane; a busca desesperada e infrutífera de Slimane pelo filho e o furto da motorizada de Slimane por adolescentes da comunidade.

Neste caso em particular, a situação oferece ao espetador um sentimento de angústia e incredulidade. Slimane não alcança ultrapassar o quadro de adversidades que se lhe apresenta num crescendo desde: o despedimento; as dificuldades burocráticas para seu projeto do barcorestaurante; as reservas iniciais da família em relação a esse sonho; as dúvidas na sua relação com Latifa; a dificuldade de comunicar com Souda; o acompanhamento dormente e silencioso da revolta de Julia; as peripécias com o jantar inaugural, terminando com a "traição" da sua comunidade, resultante da perversa e cruel brincadeira relacionada com o roubo da motorizada.

Na terceira sequência do filme, as duas cenas que se vão alternando - dança de Rym e tentativa de recuperação da motorizada de Slimane - estão isentas de diálogos. Aqui a voz foi anulada pela música e por ruídos. O som diegético conduz o espetador ao desfecho da estória, por um lado, através da música que acompanha a dança de Rym e que inebria os convidados, fazendo-os esquecer a falha de serviço do restaurante; e por outro, na medida da cada vez mais ofegante respiração de Slimane, que anuncia a irreversibilidade da catástrofe.

A máxima de Brillat-Savarin, na sua obra anteriormente referida, A fisiologia do gosto, defende que «entreter um convidado é encarregar-se de sua felicidade durante o tempo todo em que estiver sob o nosso teto». ${ }^{3}$ Trata-se do mote que prevalece ao longo do jantar inaugural do barcorestaurante. Importa questionar se esse objetivo é alcançável ou alcançado.

O final do filme, apesar de não se adivinhar feliz, permanece uma incógnita. São apresentadas sugestões ao espetador. Cabe a cada um escolher o terminus. Os convidados recebem o cuscuz de Latifa? Consegue ela superar a falta desse ingrediente com a limitada experiência que tem a cozinhar? Slimane sente-se apenas mal ou morre?

\section{Referências}

1. Kiple KF. Uma história saborosa do mundo. Dez milénios de globalização Cruz Quebrada: Casa das Letras; 2008. 417 p.

2. Kechiche A, direção. O segredo de um cuscuz [filme]. França: Pathe Distribution; 2007. 151m.

3. Brillat-Savarin JA. A fisiologia do gosto. São Paulo: Companhia das Letras; 1995. 352 p.

4. Galuppo MC. Ensaio sobre a filosofia da "fisiologia do gosto". Ciência e Conhecimento 2006; 2(8):93-124. 
5. Cascão R. À volta da mesa: sociabilidade e gastronomia. In: Mattoso J, Vaquinhas I, organizadores. História da vida privada em Portugal. v. 3: a época contemporânea. Lisboa: Círculo de Leitores; 2010. p. 56-91.

6. Santos CRA. A alimentação e o seu lugar na história: os tempos da memória gustativa. História: Questões \& Debates 2005; 42:11-31.

7. Cascão R. Em casa: o quotidiano familiar. In: Mattoso J, Vaquinhas I, organizadores. História da vida privada em Portugal. v. 3: a época contemporânea. Lisboa: Círculo de Leitores; 2010. p. 236-244.

8. O Archivo Pittoresco: semanário illustrado. Castro e Irmão, tomo II; 1859.

9. Pitte JR. Nascimento e expansão dos restaurantes. In: Flandrin JL, Montanari M, organizadores. História da alimentação: da idade média aos tempos actuais. Lisboa: Terramar; 2001. p. 751-762.

10. Santos CRA. A Alimentação e o seu lugar na História: os tempos da memória gustativa. História. Questões \& Debates; 2005; 42:11-31.

11. Silva CRB, Onofre LF. O cinema como representação da identidade cultural. In: XIII Encontro de História Anpuh-Rio; 04-07 ago. 2008; Rio de Janeiro. 4p. Disponível em: http://encontro2008. rj.anpuh.org/resources/content/anais/1215525931_ARQUIVO_artigoparaANPUH.pdf

12. Baptista M, Mascarello F. Cinema mundial contemporâneo. Campinas, SP: Papinus; 2008. 224 p.

13. Imigrantes menos segregados em França. Açoriano Oriental [Internet]. [acesso em: 6 ago. 2015]. Disponível em: http://www.acorianooriental.pt/noticias/ver/215380

14. Nadalini AP. A razão gulosa: filosofia do gosto. História: Questões \& Debates 2011; 54:283-286.

15. Envelhecimento e imigração. Imigrantes [Internet]. [acesso 6 ago. 2015]. Disponível em http:// imigrantes.no.sapo.pt/page3Envelhecimento.html

16. Journot MT. Vocabulário de cinema. Lisboa: Edições 70; 2005. 82 p. 
